Bull. Mater. Sci., Vol. 6, No. 2, May 1984, pp. 177-192. (C Printed in India.

\title{
Hydrothermal growth of $\mathrm{A}^{\mathrm{II}} \mathrm{B}^{\mathrm{VI}}$ semiconductors
}

\author{
V A KUZNETSOV, I P KUZMINA and I M SYLVESTROVA \\ Institute of Crystallography of USSR Academy of Sciences, Leninsky pr. 59, Moscow 117333, \\ USSR
}

\begin{abstract}
Hydrothermal method is used for growing $\mathrm{ZnO}, \mathrm{ZnS}$ and $\mathrm{HgS}$ single crystals. This method is more advantageous compared to the other ones and enables one to obtain large bulky crystals of technically convenient habit with low concentration of defects. Some physical properties of these single crystals were studied and active elements for the new advanced piezoelectric, electro-optic and laser devices are reported.
\end{abstract}

Keywords. Semiconductors; hydrothermal growth; piezoelectric; electro-optic; laser devices.

\section{Introduction}

$\mathbf{A}^{\mathrm{II}} \mathbf{B}^{\mathrm{VI}}$ semiconductors - zinc oxide and sulphide, mercury sulphide - are widely known as the advanced materials for different fields of technology due to the combination of various physical properties. Interest in these compounds was stimulated in recent years by the development of new methods of growth and possibilities of studying more profound properties. Thus, detailed investigation of zinc oxide elastic and electric characteristics puts this material in the forefront among the possible high-temperature piezoelectrics. Cubic $\mathrm{ZnS}$ is a potentially useful material for optical shutters and electro-optical modulators. Cinnabar, or mercury sulphide, can be used where a combination of acousto-optical and piezoelectric properties is required. Piezoelectric modulus of Cinnabar is greater by an order of magnitude, than that of quartz while electromechanical coupling coefficient is two times larger. The acousto-optical interaction coefficient $\left(M_{2}\right)$ for $\lambda=632 \mathrm{~nm}$, and longitudinal wave propogating along the optical axis with $2.45 \times 10^{5} \mathrm{~cm} / \mathrm{sec}$ rate, is $690 \times 10^{-18} \mathrm{sec}^{3} / \mathrm{g}$. This value is comparable with that of $\mathrm{TeO}_{2}$, used in optoacoustical devices. The large value of rotation of plane of polarization and other interesting properties of Cinnabar are also well-known.

The new prospects of technical application of the above materials demand good crystals and methods for obtaining them. The crystal should possess: high optical homogeneity, perfect structure and thechnically convenient habit. Traditional methods of growing $\mathrm{ZnO}, \mathrm{ZnS}$ and $\mathrm{HgS}$ single crystals (from a melt, vapour phase, flux) do not always meet these requirements.

Thus, the Stockbarger's technique, developed for growing zinc sulphide from the melt at 50-200 atm. of inertial gas pressure (Shternberg et al 1962; Kuznetsov 1964; Ananiev 1968; Kozielski 1967; Sysoev 1972; Obuhova et al 1977) enables one to obtain large $\mathrm{ZnS}$ crystals up to $40 \mathrm{~mm}$ in size (Kozielski 1967), (this method is not practically used for $\mathrm{ZnO}$ and $\mathrm{HgS}$ because of high melting point and high vapour pressure at melting point), but crystals grown by this method are structurally inhomogeneouscontaining a high concentration of packing faults and the combination of the cubic and hexagonal $\mathrm{ZnS}$ modifications (the cubic one being larger in proportion). Under 
crossed polarizers the crystal produces a pattern of alterating dark and light lines, indicative of its optical inhomogeneity, making it impossible for use in electrooptics.

In spite of numerous attempts, the flux method failed to provide large bulky $\mathrm{ZnO}$, $\mathrm{ZnS}$ and $\mathrm{HgS}$ crystals. For $\mathrm{ZnO}$ the slow cooling of zinc oxide solution in lead fluoride melt (Kashyap 1973; Nielson and Dearborn 1960) from 1150 down to $800^{\circ} \mathrm{C}$ enabled to obtain large, but very thin $\mathrm{ZnO}$ plates. The same results were obtained by the other workers (Wolff and Labelle 1965; Chase and Osmer 1967; Timofeeva 1965; Wanklyn 1970). Besides the "inconvenient" habit, the flux grown $\mathrm{ZnO}$ crystals are nonstoichiometric, extremely heterogeneous and contain high concentration of impurities and melt inclusions.

The flux method yields only small zinc and mercury sulphide crystals of several mm in size (Harsy 1968; Babansky et al 1971; Chernyshev and Babansky 1977; Laudise 1963; Mita 1962; Parker and Pinnel 1968; Linares 1968; Samelson and Brophy 1961; Garner and White 1970; Nistor et al 1980). As a rule they are very faulty, contain large amount of melt inclusions and have dendrite morphology. However, ZnS obtained by this method proved to be perfect enough. Practically, $\mathrm{ZnS}$ crystals, grown at $575^{\circ} \mathrm{C}$ (Nistor et al 1980), were cubic. This fact shows, that on the contrary to melt methods, $\mathrm{ZnS}$ crystallization at low temperatures (much lower, than wurtzite-sphalerite phase transition point $\left(1020^{\circ}\right)$, enables to obtain crystals with high structure homogeneity.

This is clearly revealed when $\mathrm{ZnS}$ crystallizes from a vapour phase. At crystallization temperatures higher than $1000^{\circ} \mathrm{C}$ (Iwanaga et al 1979; Scharowsky 1953; Park and Reynolds 1967; Dodson and Savage 1968; Nielson 1968; Hirose 1971) the crystals were characterized by the high packing faults concentration like the melt grown ones. Under polarized light they produce the clear pattern of dark and light lines similar to the melt grown samples. Crystals were small, and only at maximum temperatures $\left(1500-1600^{\circ} \mathrm{C}\right)$ samples of length $30-40 \mathrm{~mm}$ and diameter $10 \mathrm{~mm}$ were obtained.

The lowering of the crystallization temperature below $1000^{\circ} \mathrm{C}$ (Neviantseva et al 1972; Rabadanov et al 1970; Piper and Roth 1953; Green et al 1958) significantly improves the perfection of the crystals-packing fault concentration falls drasticallyand there are even some evidences of pure cubic $\mathrm{ZnS}$ formation at $770-900^{\circ} \mathrm{C}$ (Piper and.Roth 1953). However, large bulky crystals more than several mm in size at such low temperatures could not be obtained.

All attempts to obtain cinnabar crystals from vapour phase resulted in growing of either faulty and apparently inhomogeneous crystals up to $7 \mathrm{~mm}$ (at $580-750^{\circ} \mathrm{C}$ ), or rather perfect, but small 1-2 mm crystals (at temperatures lower than $344^{\circ} \mathrm{C}$ ) (Brafman et al 1964; Brafman and Steinberger 1966; Rumiantsev 1965).

Much progress was achieved in developing methods for growing $\mathrm{ZnO}$ from the vapour phase--(Rumiantsev et ai 1965; Alexander et al 1970; Lendway 1971; Sasaki 1975; Shichiri et al 1978; Russel and Woods 1979; Pashkovsky et al 1961; Carloon 1967; Pottor and Barnes 1978; Faile 1978). These methods are based either on oxidation of zinc chalcogenides by oxygen or water vapour (Pashkovsky et al 1961; Carloon 1967), or on oxidation of zinc vapour by oxygen (Lendway 1971) at $1150-1350^{\circ} \mathrm{C}$. The latter enabled to obtain some $\mathrm{ZnO}$ crystals of $7 \times 7 \mathrm{~mm}^{2}$ in size (Shichiri et al 1978; Russel and Woods 1979), but the yield of crystals was small, and the samples were mainly needles with the length not more than $10 \mathrm{~mm}$. Moreover as grown $\mathrm{ZnO}$ crystals are highly nonstoichiometric.

Thus, each of the above methods results in specific faults in the crystals. None of them meets the requirements specified above. Crystallization at relatively high 
temperatures results in noticeable nonstoichiometry (for $\mathrm{ZnO}$ ) and structural inhomogeneity (for $\mathrm{ZnS}, \mathrm{HgS}$ ).

Lowering of the crystallization temperature significantly improves the crystal quality, but the small dimensions exclude their wide practical application. It is difficult to choose a versatile method which enables growth of crystals for all applications, but in the light of earlier discussion, combining low crystallization temperatures with the possibility of obtaining large crystals seems to be the most advanced one.

The present work discusses growth of $\mathrm{ZnO}, \mathrm{ZnS}$ and $\mathrm{HgS}$ by the hydrothermal method. Relatively low crystallization temperatures $-200-400^{\circ} \mathrm{C}$ (i.e. much lower than their melting and phase transition points) enable one to reduce the amount of faults which are characteristic for high temperature samples. Moreover, by varying chemical crystallization conditions, it is possible to control the defect structure and stoichiometry and by continuing of the process it is possible to obtain large crystals. Thus, the hydrothermal method seems to be the most advanced one meeting all the requirements.

\section{Methods}

The hydrothermal method is based on the crystallization of a substance from overheated aqueous solutions at pressures (usually $100-2000 \mathrm{~kg} / \mathrm{cm}^{2}$ ) (Michaeiski et al 1979). The process is carried out in the special steel autoclaves. In the more often used variant of 'direct temperature drop' method the initial charge is placed in the lower part of the vessel, where the temperature is maintained higher, than in the upper part. The latter contains a seed crystal. Temperature drop $(\Delta T)$ between the zones of growth and dissolution leads to a convection inside the autoclave: in the lower zone, the solution gets saturated with the charge, heats up and moves to the upper zone. It cools here, becomes supersaturated and the excess substance condenses on the seed. The cooled solution goes down and the process repeats until all the initial charge is transferred to the upper zone. We have used this method in this work. The parameters that are varied: supersaturation (expressed in terms of supercooling $\Delta T$ for convenience), composition and concentration of the solution, seed orientation and temperature. The experiments have shown, that pressure was not significant in our cases, except in some special situations.

\subsection{Growth of $\mathrm{ZnO}$ crystals}

The growth was performed in $\mathrm{KOH}$ and $\mathrm{NaOH}$ solutions, where $\mathrm{ZnO}$ solubility reaches a significant value at elevated temperatures (Laudise and Caporaso 1964; Anamov et al 1972; Kuznetsov and Lobachov 1972; Kuzmina et al 1970). The solutions contained the adding of $\mathrm{LiOH}$, which influenced the morphology, growth rates and quality (Laudise and Caporaso 1964). Optimum solution concentrations, crystallization temperatures and temperature gradients were found experimentally. The initial charge contained chemical $\mathrm{ZnO}$ agent and polycrystalline $\mathrm{ZnO}$, hydrothermally synthesized beforehand. The first seeds were grown from the flux according to Kashyap (1973) and Nielson and Dearson (1960) and later on replaced by the hydrothermal ones. In some cases $\mathrm{ZnO}$ needles and plates, grown by gas transport reactions, were used as seeds. Our preliminary studies have shown, that growth of the crystal is fastest in the $(0001)$ direction. So, the plates oriented parallel to (0001) planes, were used as seeds. The 
temperature range under study was $200-450^{\circ} \mathrm{C}$. Figure 1 presents the concentration dependence of (0001) plane growth rate for $\mathrm{ZnO}$ at $T=270^{\circ} \mathrm{C}, \Delta T=70^{\circ} \mathrm{C}(\Delta T$ is measured along the outside autoclave wall). The exponential form of the curve is universal, i.e. is not influenced by temperature and temperature gradients.

Figure 2 presents $(0001),(0001),(1010)$ growth rates vs temperature for two temperature gradients $\left(\Delta T_{1}=50^{\circ} \mathrm{C}, \Delta T_{2}=75^{\circ} \mathrm{C}\right)$ in $5.15 \mathrm{~m} \mathrm{KOH}+1.2 \mathrm{~m} \mathrm{LiOH}$ solution. One can see that the growth rates increase with temperature, but their relationship decreases. The values obtained for critical supersaturation (expressed in terms of $\Delta T_{\text {cr }}$, have shown, that $\Delta T_{\mathrm{cr}}$ is minimum for (0001) plane, which grows noticeably at low supersaturations (Lobachev et al 1982).

Since the growth rates in $\mathrm{KOH}$ solutions are higher than in $\mathrm{NaOH}$ solution under similar conditions, $\mathrm{KOH}$ solutions were used. $\mathrm{ZnO}$ growth kinetics was not practically influenced by the pressure changes within $100-600 \mathrm{~kg} / \mathrm{cm}^{2}$, however the crystal quality declined significantly at lower pressures $\left(<100 \mathrm{~kg} / \mathrm{cm}^{2}\right)$. The above experimental data show that the large growth rates of $\mathrm{ZnO}(>0.1 \mathrm{~mm} /$ day) can be achieved within the wide temperature and solution concentration ranges. For better understanding of the

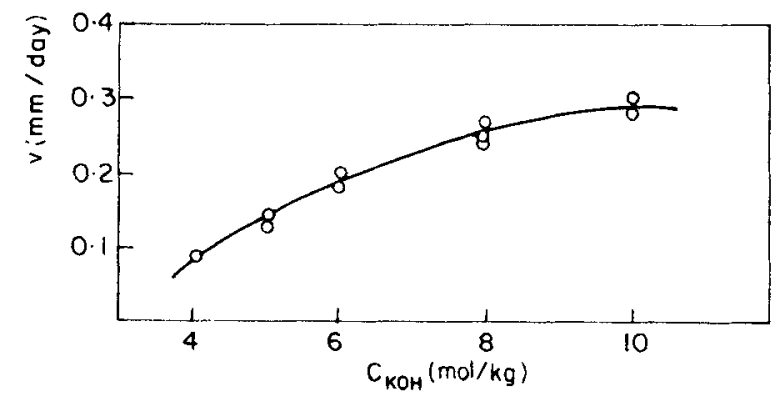

Figure 1. $\mathrm{KOH}$ concentration dependence of (0001) plane growth rate for $\mathrm{ZnO}$.

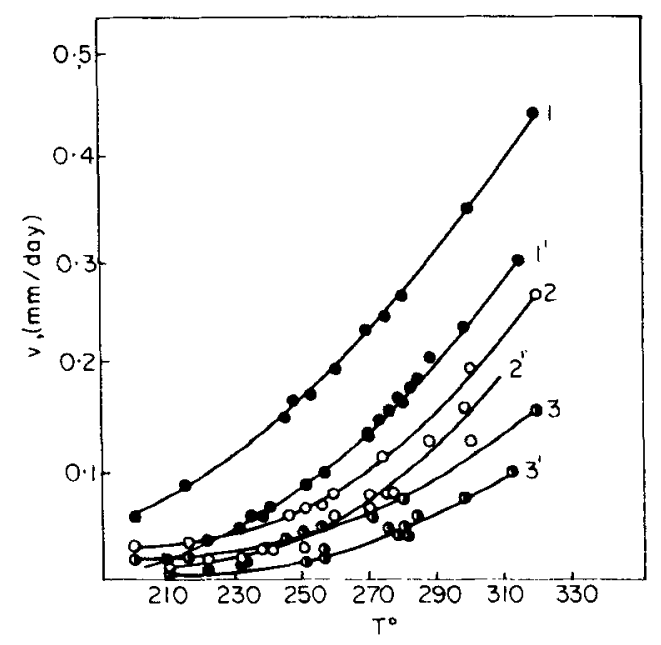

Figure 2. Temperature dependence of (0001) (curves 1, $\left.1^{\prime}\right),(0001)$ (curves 2, 2') and (10T0) (curves $\left.3,3^{\prime}\right)$ growth rates for $\mathrm{ZnO}$. $\left(\mathrm{C}_{\mathrm{KOH}}=5.15 \mathrm{~m} / \mathrm{kg}, \mathrm{C}_{\mathrm{LiOH}}=1.2 \mathrm{~m} / \mathrm{kg}, \Delta T=75^{\circ}\right.$ and $T=50^{\circ}$ for curves $1-3$ and $1^{\prime}-3^{\prime}$ respectively.). 
crystallization conditions cathodoluminescence study of variously grown $\mathrm{ZnO}$ crystals was performed (Lobachev et al 1977). The spectral analysis, mainly of the halfwidth of narrow resonance cathodoluminescence lines and the possibility of their resolution, shows, that the crystals grown at $250-300^{\circ} \mathrm{C}$, with supersaturations corresponding to $\Delta T=40-50^{\circ} \mathrm{C}$ have better perfection (Laudise and Caporaso 1964; Kuzmina et al 1970; Lobachev et al 1982). The crystal perfection declines, when the temperature lies outside the above range.

Assuming all the experimental data, we have optimized $\mathrm{ZnO}$ growth conditions: crystallization temperature $=260-290^{\circ} \mathrm{C}, \Delta T=40-50^{\circ} \mathrm{C}$, pressure $\sim 600 \mathrm{~kg} / \mathrm{cm}^{2}$, concentration of $\mathrm{KOH}=5-10 \mathrm{~m}, \mathrm{LiOH}=$ up to $1.5 \mathrm{~m}$. (0001) growth rate was $0.1-0.25 \mathrm{~mm} /$ day under these conditions, which enabled one to obtain bulky $\mathrm{ZnO}$ crystals of several $\mathrm{cm}^{3}$ in size in the prolonged experiments. Figure 3 represents one of such crystals.

Despite the low crystallization temperatures, hydrothermal $\mathrm{ZnO}$ crystals, as well as other grown ones, are not stoichiometric enough, which might be conditioned among other reasons by the reductional medium inside the autoclave. The excess zinc atoms (their concentration may reach $10^{15}-10^{19} \mathrm{~cm}^{3}$ ), located in the interstitials, and oxygen vacancies are fixed in the crystals. These point defects are responsible for the light yellow colouration of the crystals (also caused by Fe impurity) and the elevated

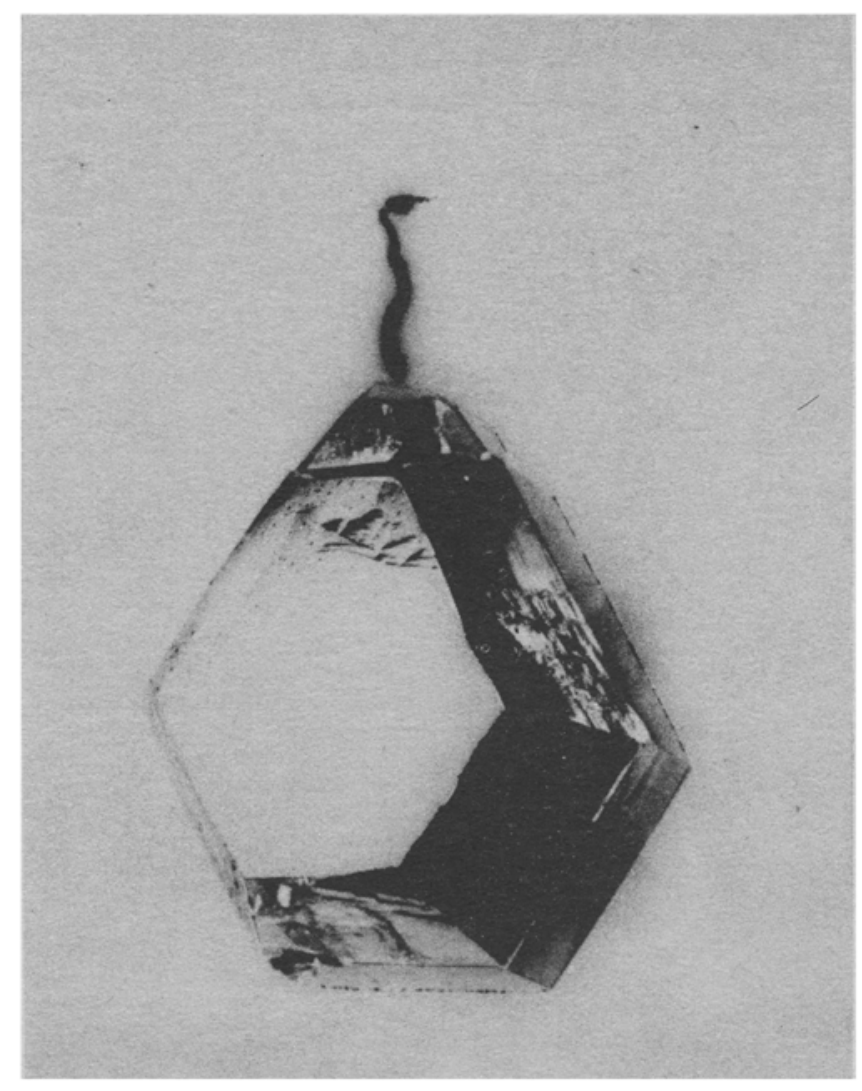

Figure 3. Hydrothermal $\mathrm{ZnO}$ crystal (natural size). 
conductivity; usual $\mathrm{ZnO}$ resistance lies within $10^{1}-10^{4} \mathrm{ohm} . \mathrm{cm}$. The annealing at $700^{\circ} \mathrm{C}$ in the presence of lithium salts (Laudise and Caporaso 1964) leads to a significant rise of resistance. Lithium doping during the annealing increases the resistance up to $10^{11} \mathrm{ohm}$. cm which broadens their practical application.

The hydrothermal growing of large, isometric $\mathrm{ZnO}$ crystals, enabled to make first evaluations of their elastic, dielectric, piezoelectric and laser properties (Croxall et al 1974; Heiland et al 1959; Tokarev et al 1975; Kurbatov et al 1980). Table 1 presents the complete set of elastic, dielectric and piezoelectric constants of $\mathrm{ZnO}$ at room temperature.

The measurements have revealed the unique feature of $\mathrm{ZnO}$ crystallization-the slight dependence of the elastic characteristics and the electromechanical coupling coefficients on temperature (figure 4). Thus, the average temperature coefficient values of the elastic constants proved to be equal within $300-700^{\circ} \mathrm{C}$ range. (in $\operatorname{grad}^{-1}$ ): $T_{S_{11}}^{E}=7.5 \times 10^{-5}, T_{S_{12}}^{E}=5.4 \times 10^{-5}, T_{S_{55}}^{E}=7.1 \times 10^{-5}, T_{33}^{D}=12.3 \times 10^{-5}, T_{55}^{D}=$ $-6.9 \times 10^{-5}$.

Coefficients of dielectric constants, measured at room temperature (in $\operatorname{grad}^{-1}$ ), are:

$$
T_{11}^{T}=4.3 \times 10^{-4}, T_{33}^{T_{3}}=4.4 \times 10^{-4} .
$$

Electromechanical coupling coefficients of $\mathrm{ZnO}$ are the largest among all the known nonferroelectrics and are practically constant up to $1000 \mathrm{~K}$. Thus, piezoelectric properties of $\mathrm{ZnO}$ are preserved in a wider temperature range than those of the widely used materials (quartz, for instance). It enabled to construct high effective piezoelectric

Table 1. ZnO elastic, dielectric and piezoelectric constants at room temperature

\begin{tabular}{|c|c|c|c|}
\hline Characteristics & $\begin{array}{c}\text { Numerical } \\
\text { value }\end{array}$ & Characteristics & $\begin{array}{c}\text { Numerical } \\
\text { value }\end{array}$ \\
\hline$s_{11}^{E}$ & 0.791 & $c_{11}^{E}$ & $20 \cdot 70$ \\
\hline$s_{33}^{E}$ & 0.72 & $c c_{33}$ & $20-95$ \\
\hline$s_{12}^{E}$ & -0.33 & $c_{12}^{E}$ & 11.77 \\
\hline$s_{13}^{E}$ & -0.235 & $c_{13}^{E}$ & 10.61 \\
\hline$s_{55}^{E}$ & $2 \cdot 23$ & $c E_{55}$ & $4 \cdot 48$ \\
\hline$s_{66}^{E}$ & $2 \cdot 42$ & $c_{66}^{E}$ & $54 \cdot 46$ \\
\hline$s_{11}^{D}$ & 0.765 & $c_{11}^{D}$ & 20.96 \\
\hline$s_{33}^{D}$ & 0.56 & $c_{33}^{D}$ & $22-1$ \\
\hline$s_{12}^{D}$ & -0.36 & $c_{12}^{D}$ & 12.04 \\
\hline$s_{13}^{D}$ & -0.17 & $c_{13}^{D}$ & $10 \cdot 13$ \\
\hline$s_{53}^{D}$ & $2 \cdot 14$ & $c c_{35}$ & $4 \cdot 61$ \\
\hline$d_{31}$ & $-5 \cdot 12$ & $e_{31}$ & -0.62 \\
\hline$d_{33}$ & $12 \cdot 3$ & $e_{33}$ & 0.96 \\
\hline$d_{15}$ & $-8 \cdot 3$ & $e_{15}$ & -0.37 \\
\hline$k_{31}$ & $0-181$ & $\varepsilon_{11}^{\prime}$ & 8.67 \\
\hline$k_{33}$ & 0.466 & $\varepsilon_{33}^{\prime}$ & $11 \cdot 26$ \\
\hline$k_{15}$ & $0-199$ & $\varepsilon_{11}^{s}$ & 8.33 \\
\hline$k_{t}$ & 0.229 & $\varepsilon_{33}^{3}$ & $8 \cdot 81$ \\
\hline
\end{tabular}

$\left(s-10^{-11} \mathrm{~m}^{2} / \mathrm{n}, d-10^{-12} \mathrm{q} / \mathrm{n}, c-10^{-10} \mathrm{n} / \mathrm{m}^{2}, e-\mathrm{q} / \mathrm{m}^{2}\right)$ 


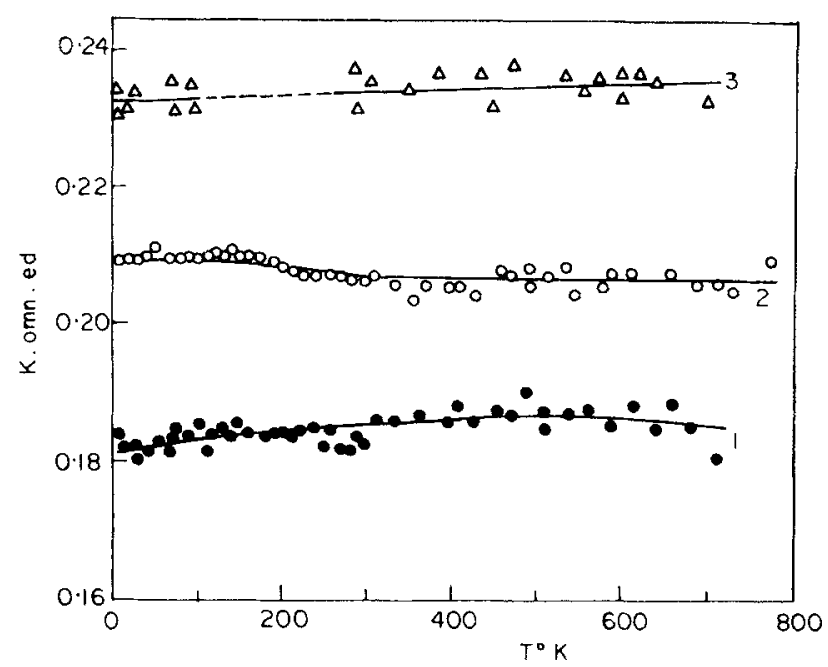

Figure 4. Electromechanical coupling coefficients temperature dependence for $\mathrm{ZnO}$. 1. $k_{31}$; 2. $k_{15}$; 3. $k_{\mathrm{t}}$ (Tokarev et al 1975).

sound transducers on lithium doped $\mathrm{ZnO}$ crystals, worktable up to $1000 \mathrm{~K}$ (Tokarev et al 1975).

$\mathrm{ZnO}$ active elements for semiconductor electron pumped lasers in uv range have also been designed (figure 5) (Kurbatov et al 1980). $\mathrm{ZnO}$ lasing spectrum presents two lines with 375 and $383 \mathrm{~nm}$ maxima and $1.5-2 \mathrm{~nm}$ halfwidth (figure 6). The value of the radiation power reaches $3-5 \mathrm{~kW}$ in 3-5 nc pulse at $80 \mathrm{~K}$ as well as at room temperature (voltage $U=115 \mathrm{kV}$, electron beam density $j=60 \mathrm{~A} / \mathrm{cm}^{2}$ ).

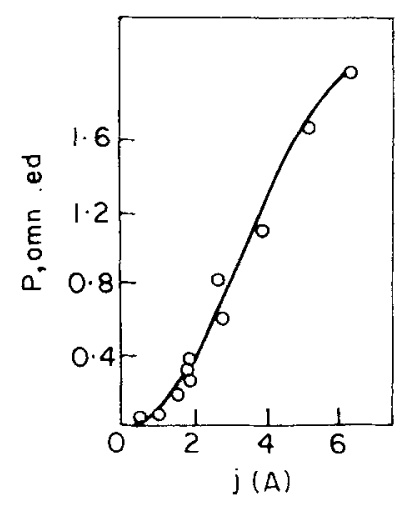

Figure 5. Pumping current I and acceleratng voltage $\mathrm{V}$ dependence of radiation pulse power $P$ for sealed lasers (Kurbatov et al 1980).

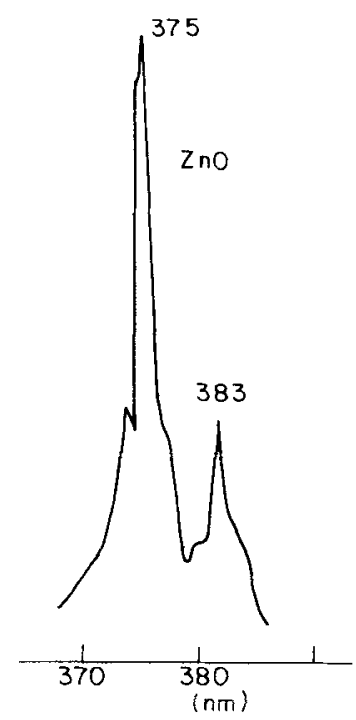

Figure 6. Lasing spectrum of $\mathrm{ZnO}$ laser targets at liquid nitrogen cooling. (Kurbatov et al 1980). 
$\mathrm{ZnO}$ laser with an output power about $300 \mathrm{~W}$ allowing filtering, has been constructed. The lasing was observed at liquid nitrogen cooling with threshold electron beam density $j=60 \mathrm{~A} / \mathrm{cm}^{2}$ and voltage $U=34 \mathrm{kV}$.

\subsection{Growth of $\mathrm{ZnS}$ crystals}

The wide stability zone of $\mathrm{ZnS}$ in hydrothermal solutions provides the fundamental possibility of usage of various media when crystal growing, which enables wide variation of physical-chemical crystallization conditions. Two procedures for $\mathrm{ZnS}$ growth are the most applied ones: in the extremely acid $\left(\mathrm{H}_{3} \mathrm{PO}_{4}\right)$ and alkaline $(\mathrm{KOH}$, $\mathrm{CsOH}$ ) solutions. The comparison of the crystals, grown under such different conditions, enabled to evaluate the influence of physical-chemical parameters on the faults present.

$\mathrm{ZnS}$ crystallization in $\mathrm{H}_{3} \mathrm{PO}_{4}$ solutions was performed at $380-450^{\circ} \mathrm{C}$ with $\mathrm{H}_{3} \mathrm{PO}_{4}$ concentration up to 50 mass $\%$. The seed crystal fast growing plane (111) growth rate reached $\sim 0.15 \mathrm{~mm} /$ day, which enabled to obtain $2-3 \mathrm{~cm}^{3} \mathrm{ZnS}$ crystals in prolonged experiments. Lowering of $\mathrm{H}_{3} \mathrm{PO}_{4}$ concentration leads to diminishing of growth rates, and its increase provides an extremely reducing condition in the autoclave (due to $\mathrm{H}_{2} \mathrm{~S}$ intensive releasing, when dissolving of the initial $\mathrm{ZnS}$ charge), which results in increasing amount of defects. First of all it caused the intense colouration of the crystals.

$\mathrm{ZnS}$ crystallization study in $\mathrm{KOH}$ and $\mathrm{CsOH}$ solutions was performed within $350-420^{\circ} \mathrm{C}$ range, at concentrations up to $10 \mathrm{~m}$. Figure 7 presents $\mathrm{KOH}$ concentration dependence of $\mathrm{ZnS}$ (111) plane growth rate. The dependence is the same in $\mathrm{CsOH}$ solutions. Temperature slightly influences $\mathrm{ZnS}$ crystallization rate, which practically does not change at constant temperature and with $\mathrm{KOH}$ concentration more than $\sim 4 \mathrm{~m}$ (figure 7). The crystal growth was performed at $380^{\circ} \mathrm{C}, \mathrm{KOH}$ and $\mathrm{CsOH}$ concentrations $\sim 8 \mathrm{~m}, \Delta T=5-10^{\circ} \mathrm{C}$. Under these conditions (111) growth rate reached $0.1 \mathrm{~mm} /$ day in $\mathrm{KOH}$ solutions and $0.07 \mathrm{~mm} /$ day $\mathrm{CsOH}$ solutions. We preferred to use $\mathrm{CsOH}$ solutions, because the crystals grown in them were more perfect, although the growth rate in $\mathrm{CsOH}$ solution was less. One such as-grown $\mathrm{ZnS}$ crystal is presented in figure 8 .

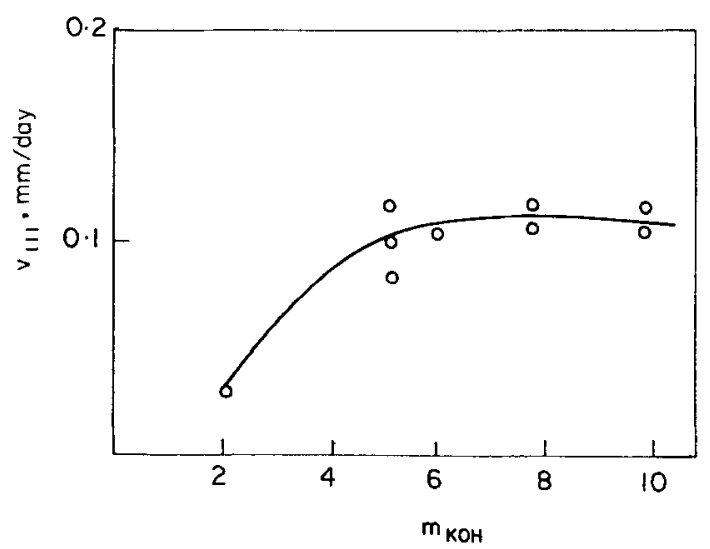

Figure 7. KOH concentrational dependence of (111) plane growth rate for $\mathrm{ZnS}\left(T=380^{\circ} \mathrm{C}\right.$, $\Delta T=8^{\circ} \mathrm{C}$ ). 


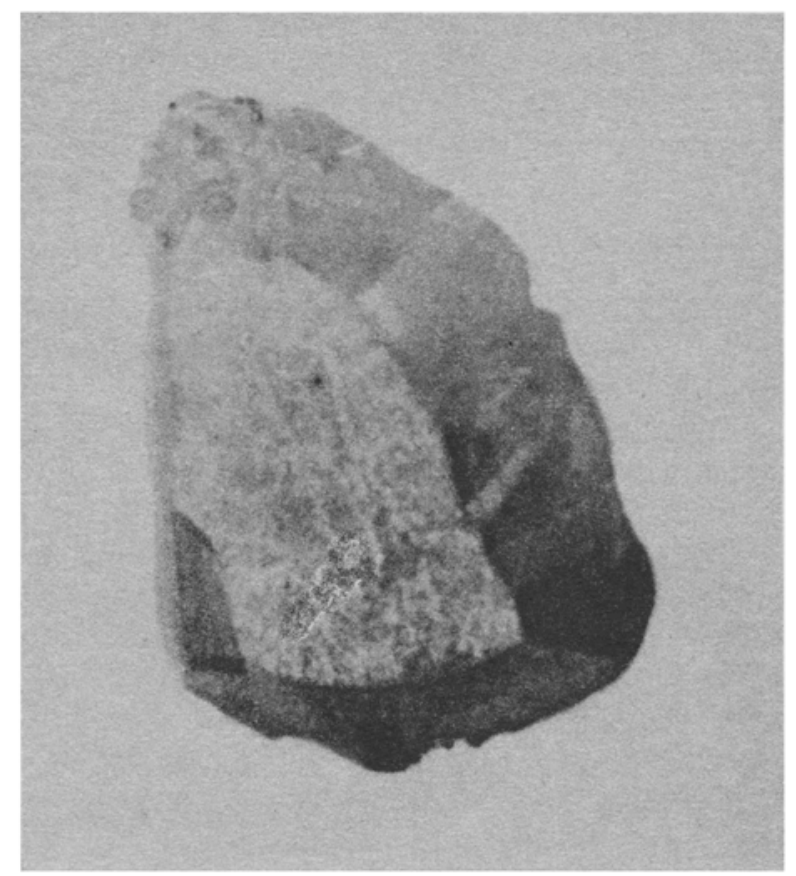

Figure 8. Hydrothermal $\mathrm{ZnS}$ crystal $(\times 4)$.

Optical and cathodoluminescence studies have shown a substantial difference in the defect structure of variously grown $\mathrm{ZnS}$ crystals (Shalimova et al 1974a, b; Morozova et al 1979; Galstian et al 1980). First of all, it is visually revealed in the different optical homogeneity of the materials. $\mathrm{H}_{3} \mathrm{PO}_{4}$ grown $\mathrm{ZnS}$ crystals are more optically homogeneous and as a rule look isotropic under crossed polarizers. Alkaline grown $\mathrm{ZnS}$ crystals are usually anisotropic. The reasons for this lie mainly in the different way of oxygen impurity trapping. Indeed, the chemical analysis showed that oxygen impurity containment in $\mathrm{KOH}$ grown $\mathrm{ZnS}$ crystals reached 0.7 at .\%, while in $\mathrm{CsOH}-$ $\sim 0.3$ at $\%$ (the quantity of oxygen impurity is correlated with that of the alkaline metal: $\mathrm{K}$ enters $\mathrm{ZnS}$ up to 0.3 at.$\%$ facilitating oxygen trapping according to the volumetric compensation principle, while $\mathrm{Cs}^{+}$concentration does not exceed $\sim 0 \cdot 1$ at . $\%$ ). Oxygen impurity concentration in $\mathrm{H}_{3} \mathrm{PO}_{4}$ grown $\mathrm{ZnS}$ crystals does not exceed 0.4 at.$\%$. Cathodoluminescence spectra provide more detailed information concerning $\mathrm{ZnS}$ defect structure. The most characteristic spectral features of various $\mathrm{ZnS}$ crystals are as follows:

335 and $415 \mathrm{~nm}$ radiation and the intense edge luminescence are characteristic for $\mathrm{H}_{3} \mathrm{PO}_{4}$ grown crystals. Such a spectrum is indicative of the high concentration of point defects, practically no packing faults, and oxygen impurity, concentrating mainly on the specific defects (radiation at $415 \mathrm{~nm}$ ).

338 and $368 \mathrm{~nm}$ radiation and the weak edge luminescence are characteristic of $\mathrm{KOH}$ and $\mathrm{CsOH}$ grown crystals. $415 \mathrm{~nm}$ radiation is not present. Such a spectrum is indicative of an elevated oxygen impurity concentration (sometimes it precipitates in the form of microscopic $\mathrm{Zn}(\mathrm{S}, \mathrm{O})$ solid phase inclusions), the very low point faults 
concentration, but higher (in comparison with 'acid' samples) packing faults concentration (not exceeding $1 \%$ ). The elevated presence of oxygen impurity in 'alkaline' $\mathrm{ZnS}$ and its precipitation in the form close to $\mathrm{Zn}(\mathrm{S}, \mathrm{O})$ solid solution result in the above mentioned optical inhomogeneity of such crystals (Morozova et al 1979). Since oxygen is less trapped in $\mathrm{CsOH}$ solutions, the crystals obtained are more optically homogeneous.

Besides optical homogeneity, the differences in $\mathrm{ZnS}$ defect structure are revealed in some other properties also. Thus, the elevated point defects concentration in acid grown samples is responsible for their higher photoconductivity and lower resistance in comparison with alkali-grown samples $\left(\sim 10^{10} \mathrm{Ohm} / \mathrm{cm}\right.$ against $\left.\sim 10^{12} \mathrm{Ohm} / \mathrm{cm}\right)$. Acid grown samples are mainly greenish-brown, while alkaline grown ones are colourless and transparent within 0.23-12 nm (Shamburov et al 1970). All these distinctions are significant for usage of $\mathrm{ZnS}$ as electro-optic material.

Figure 9 presents the typical light transmission curves of 'alkaline' (111) ZnS cuts at transverse electro-optic effect under crossed polarisers $v s$ voltage $\mathrm{V}$ (Shamburov et al 1970). One can observe the initial light transmission, characterizing optical homogeneity of the crystals, to be about $1.5-2 \%$. The measured halfwave voltage is $\sim 10.5 \mathrm{kV}$ at $630 \mathrm{~nm}$ and falls to $\sim 8.5 \mathrm{kV}$ at $500 \mathrm{~nm}$ (figure 10). The residual voltage of 'acid' crystals is lower than that of 'alkaline' ones, but the halfwave voltage varies from $\sim 8$ to $\sim 15 \mathrm{kV}$. The latter might be conditioned by the screen effects due to the electric field application and higher mobility charge carriers in such crystals.

Thus, on account of the homogenous nature of $\mathrm{ZnS}$ obtained by hydrothermal method, the crystals can be used in optical shutters and light modulators within 0.4-13 nm. Note, that cubic $\mathrm{ZnS}$, on the contrary to uniaxial crystals, enables to create wide angle modulators, necessary, e.g. in convergent beams modulation. So, it is possible to obtain $100 \%$ modulation depth for the beam converging at $12^{\circ}$, when applying the transverse electro-optic effect in (110) cut at $\langle 1 \overline{10}\rangle$ field orientation; the crystals were 4 and $0.4 \mathrm{~mm}$ in light and field directions respectively (Shamburov et al 1970).

$\mathrm{ZnS}$ transparency in uv region enables their effective usage for overfrequency

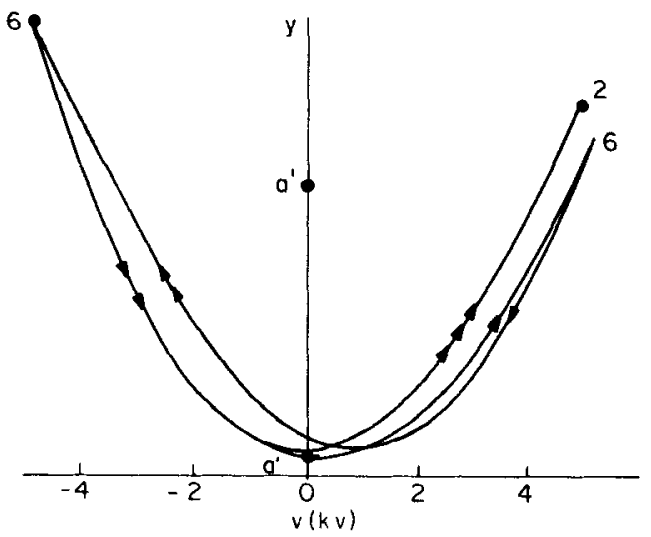

Figure 9. Light transmission curve for transverse electro-optic effect in $\mathrm{ZnS}$ crystal (111) cut when crossed polarizers. The curve looks like a "butterfly" hysteresis loop (Shambunov et al 1970). 


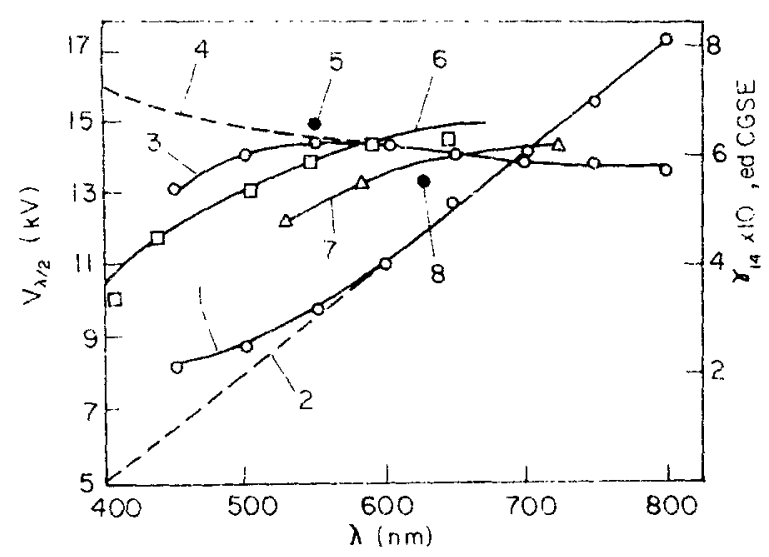

Figure 10. Wave length $(\lambda)$ dependence of halfwave voltage $V_{\lambda / 2}$ and electrooptical coefficient $r_{41}$ (Shamburov et al 1970). 1. $V_{\lambda ; 2}(\lambda) ; 2$. the extension of curve 1 linear part; 3. $r_{41}(\lambda)$; the curve 3 extension, corresponding to curve $2 ; 5,6,7,8-r_{41}(\lambda)$ for natural $\mathrm{ZnS}$.

Table 2. Optical characteristics of $\mathrm{ZnS}$ and $\mathrm{ZnSe}$.

\begin{tabular}{lcc}
$\lambda \mathrm{nm}$ & \multicolumn{2}{c}{$M_{\omega} \cdot \tau_{\lambda}{ }^{\circ}{ }^{\circ}$} \\
\hline & $\mathrm{ZnS}$ & $\mathrm{ZnSe}$ \\
\hline 0.44 & 16 & - \\
0.53 & 17 & 16 \\
0.63 & 18 & 21 \\
\hline
\end{tabular}

$\tau_{\lambda}$-modulation depth; $M_{\omega}$-crystal transparency.

modulation of the radiation with $<0.5 \mathrm{~nm}$ (Kuznetsov et al 1980). Table 2 compares the characteristics of $\mathrm{ZnS}$ and $\mathrm{ZnSe}$, widely used for this purpose now. At 0.53 nm ZnS is more effective than $\mathrm{ZnSe}$, and below $0.53 \mathrm{~nm} \mathrm{ZnSe}$ is not used because of high absorption. So, $\mathrm{ZnS}$ enables to perform overfrequency modulation of the radiation with $\lambda<0.5 \mathrm{~nm}$.

The spectra of electron pumped $\mathrm{ZnS}$ lasing have been studied (Kurbatov et al 1980). Laser target resonators have been specially made by spalling along the cleavage plane. Minimum $\mathrm{ZnS}$ lasing voltage was $40 \mathrm{kV}$ at threshold electron beam density of $11 \mathrm{~A} / \mathrm{cm}^{2}$. A set of lines within $330-337 \mathrm{~nm}$ range with the most intensive one at $336 \mathrm{~nm}$ ( $\sim 1.5 \mathrm{~nm}$ halfwidth (figure 11) was fixed in the lasing spectrum. The radiation power was $500-700 \mathrm{~W}$ in 3-5 nc pulse at $80 \mathrm{~K}$. The lasing parameters are indicative of the high laser quality of $\mathrm{ZnS}$, radiating in the most shortwave range in comparison with other known materials.

\section{$2.3 \alpha-H g S$ crystallization}

Unlike $\mathrm{ZnS}$, the narrow stability zone of cinnabar substantially limits the solvents selection for crystal growth (Kuznetsov et al 1973; Tondic et al 1972). Rather intensive $\mathrm{HgS}$ recrystallization (without decomposition) was found to occur in sodium and potassium hydrosulphide solutions with pH 9-13 (Efremova et al 1976). HgS solubility 


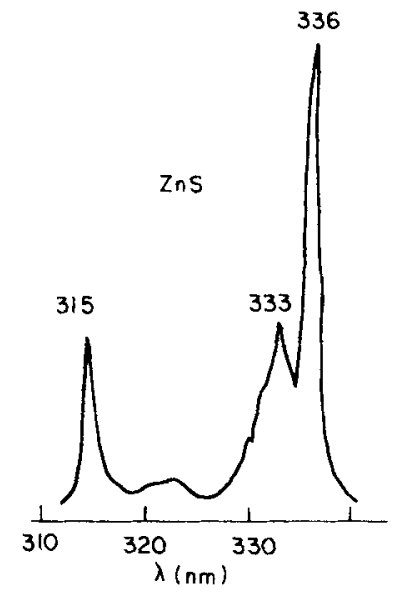

Figure 11. Lasing spectrum of $\mathrm{ZnS}$ laser targets at liquid nitrogen cooling (Kurbatov et al 1980).

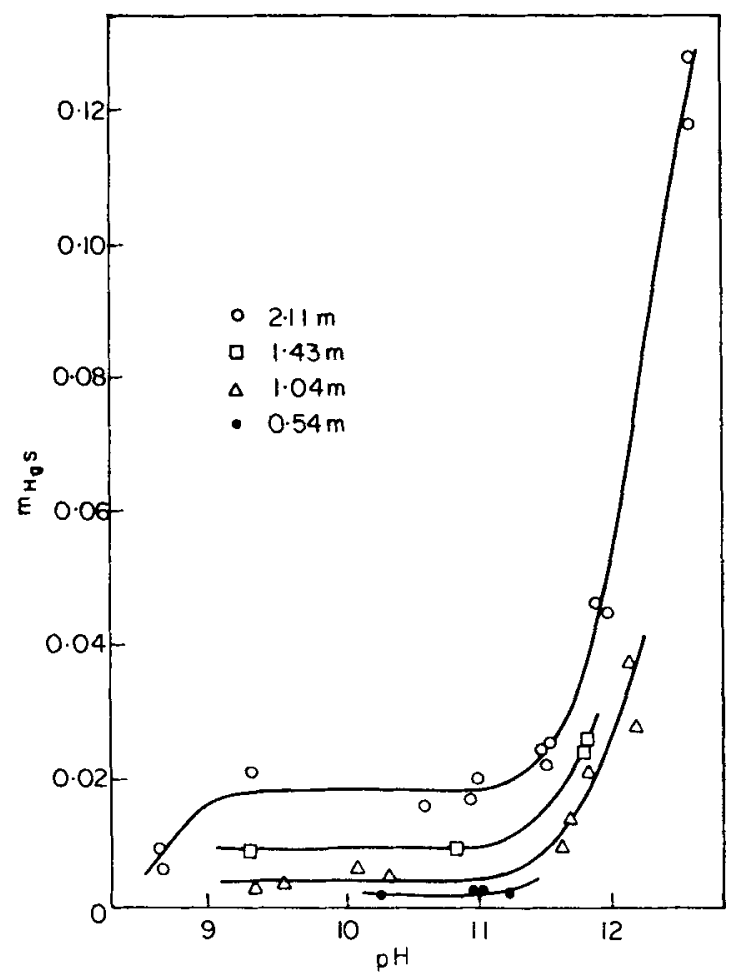

Figure 12. $\alpha-\mathrm{HgS}$ solubility within $8 \cdot 5-12.5 \mathrm{pH}$ range in NaHS solutions of different concentrations (Efremova et al 1976).

study in NaHS solutions enabled to choose two $\mathrm{pH}$ zones (figure 12): the one, where $\mathrm{HgS}$ solubility does not depend on $\mathrm{pH}(9-11 \cdot 5)$, the other, where solubility rises when $\mathrm{pH}$ increases $(\mathrm{pH}>11 \cdot 5)$. Such solubility behaviour is conditioned by various compositions of the $\mathrm{Hg}$ complexes formed in solution (Efremova et al 1982). 
Table 3. Growth rates of $\mathrm{HgS}$ on (0001) and (1010).

\begin{tabular}{lrlc}
\hline Solution & pH & \multicolumn{2}{c}{$\mathrm{V}(\mathrm{mm} /$ day $)$} \\
\cline { 3 - 4 } & & $(0001)$ & $(1070)$ \\
\hline $\mathrm{Na}_{2} \mathrm{~S}+\mathrm{H}_{2} \mathrm{~S}$ & $9-11$ & 0.5 & $0-3$ \\
$\mathrm{Na}_{2} \mathrm{~S}+\mathrm{H}_{2} \mathrm{~S}$ & $12-13$ & $0-1$ & $0-05$ \\
$\mathrm{Na}_{2} \mathrm{~S}+\mathrm{NH}_{4} \mathrm{Cl}$ & $12-13$ & $0-05$ & $0-02$ \\
$\mathrm{Na}_{2} \mathrm{~S}+\mathrm{NaHCO}_{3}$ & $12-13$ & 0.2 & $0-07$ \\
\hline
\end{tabular}

(Temperature $-280^{\circ} \mathrm{C} ; \Delta T-30^{\circ} \mathrm{C}$ )

Assuming the solubility data, cinnabar crystallization in NaHS solutions was performed within 9-11 and 12-13 pH intervals. The solutions with such pH values were obtained by: the saturation of $\mathrm{Na}_{2} \mathrm{~S}$ solution $(\mathrm{pH}>13$ ) with hydrosulphide, by addition of ammonium chloride or sodium bicarbonate or both to $\mathrm{Na}_{2} \mathrm{~S}$ solution. The latter was used for preparing only of $12-13 \mathrm{pH}$ solutions. Table 3 presents $\mathrm{HgS}(0001)$ and (1010) growth rates in these solutions.

In $\mathrm{Na}_{2} \mathrm{~S}$ solutions, saturated with hydrosulphide up to $\mathrm{pH}=9-11, \mathrm{HgS}$ growth rates did not exceed $0.05 \mathrm{~mm} /$ day. At the same time, as-grown crystals were usually defective, with large amount of gas-liquid inclusions and obvious columnar crystallization traces. Moreover partial decomposition of $\mathrm{HgS}$ was sometimes found under these conditions, apparantly due to the low redox potential, when considerable hydrosulphide was saturated into the initial $\mathrm{Na}_{2} \mathrm{~S}$ solution.

Within $12-13 \mathrm{pH}$ interval cinnabar growth rates are noticeably higher in the same $\left(\mathrm{Na}_{2} \mathrm{~S}+\mathrm{H}_{2} \mathrm{~S}\right)$ solutions; the amount of gas-liquid inclusions starts decreasing and columnar crystallization traces start vanishing. However, it was not always possible to avoid partial $\mathrm{HgS}$ decomposition. Moreover, saturation of $\mathrm{Na}_{2} \mathrm{~S}$ with hydrosulphide solution is rather technically complicated. So, in subsequent experiments we added ammonium chloride or sodium bicarbonate to $\mathrm{Na}_{2} \mathrm{~S}$ solutions to reach a $\mathrm{pH}$ of 12-13. In the first case $\mathrm{HgS}$ growth rate was lowered (see table 3 ). $\mathrm{HgS}$ decomposition with the formation of metallic mercury was found in none of the experiments. When sodium bicarbonate was added to $\mathrm{Na}_{2} \mathrm{~S}$ solution, the growth rates, on the contrary, increase, but $\mathrm{HgS}$ decomposes, indicating the considerable redox conditions change inside the autoclave in the presence of sodium bicarbonate. The best results were obtained using $\mathrm{Na}_{2} \mathrm{~S}+\mathrm{NH}_{4} \mathrm{Cl}+\mathrm{NaHCO}_{3}$ solutions ( $\mathrm{pH}=12-13$ ). The growth rates in these solutions reached $0 \cdot 1-0.15 \mathrm{~mm} /$ day without $\mathrm{HgS}$ decomposition. As-grown $\mathrm{HgS}$ crystals were $1.5 \mathrm{~cm}$ in size (see figure 13 ).

The samples of necessary orientation and shape for piezoelectric, elastic and dielectric constants measurements were made from the grown crystals. The bars and plates cut from the pure crystal did not exceed $4.8 \times 2.5 \times 1.5(-1.8) \mathrm{mm}$ and $6 \times 4 \times 1.1 \mathrm{~mm}$ in respective size. Maximum dimensions of the parallelepipeds were of 6 $\times 4 \times 5 \mathrm{~mm}^{3}$.

Piezoelectric properties of $\alpha-\mathrm{HgS}$ are described by two independent moduli $\mathrm{d}_{11}$ and $d_{14}$. The resonance-antiresonance method was used for their measurements. The compression-tension oscillations of $X$-cut bar with the length along $Y$, excited by $\mathrm{X}$-directed electric field and countour shear and thickness shear vibration of $\mathrm{Y}$-cut plates were measured at room temperature. 


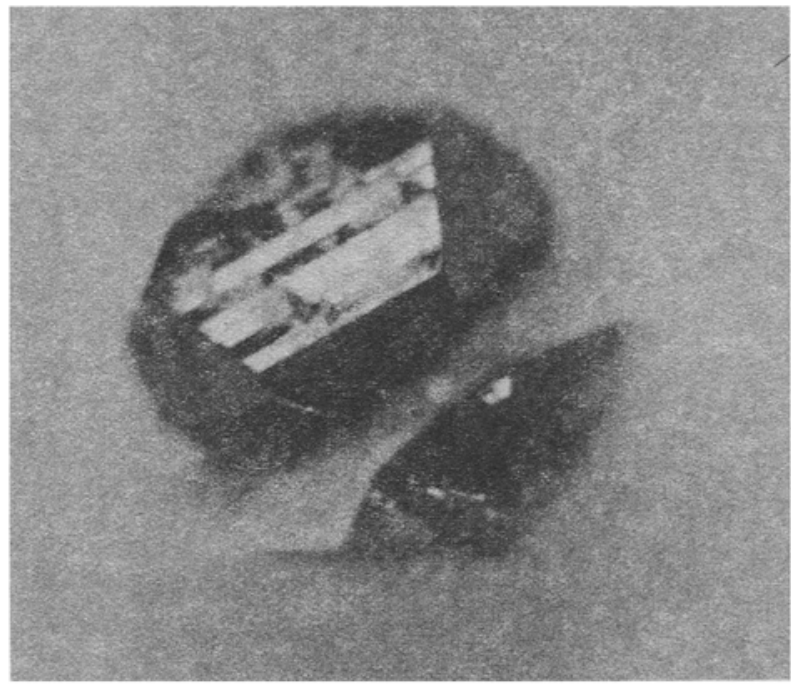

Figure 13. Cinnabar $(\alpha-\mathrm{HgS})$ crystal, grown in the sulphide-chloride carbonate solution $(\times 2)$.

The independently measured values of the electromechanical coupling coefficients and dielectric constants enabled to calculate the effective values of piezoelectric moduli $\mathrm{d}_{i k}$.

The velocities of ultrasonic wave propagation along various crystallographic directions were measured by the pulse ultrasonic method. It enabled to calculate the effective value of elastic modulus and all its six independent constants, characterizing the elastic constant tensor of a crystal.

Table 4. Dielectric, elastic and piezoelectric constants of cinnabar and quartz crystals

\begin{tabular}{|c|c|c|c|}
\hline \multirow{3}{*}{$\begin{array}{l}\text { Cinnabar } \\
\text { Piezoelectric } \\
\text { modulus, } 10^{-12} \mathrm{k} / \mathrm{n}\end{array}$} & & \multicolumn{2}{|c|}{ Quartz } \\
\hline & Our data & $a$ & $b$ \\
\hline & $\begin{array}{l}d_{11}=-21 \cdot 3 \\
d_{14}=15.43\end{array}$ & $\begin{array}{r}-19 \cdot 0 \\
+2 \cdot 0\end{array}$ & $\begin{array}{l}-2.25 \\
+0.86\end{array}$ \\
\hline $\begin{array}{l}\text { Elastic compliances, } \\
10^{-12} \mathrm{~m}^{2} / \mathrm{n}\end{array}$ & $\begin{array}{l}s_{11}=42 \cdot 82 \\
s_{12}=-17.8 \\
s_{13}=-4.31 \\
s_{14}=-32.2 \\
s_{33}=21 \cdot 11 \\
s_{44}=80.75 \\
s_{66}=121.24\end{array}$ & $41 \cdot 0$ & $\begin{array}{c}12.79 \\
-1.535 \\
-1.1 \\
-4.46 \\
956 \\
19.78 \\
28.65\end{array}$ \\
\hline Dielectric constants & $\begin{array}{l}\varepsilon_{11}^{T}=17 \cdot 6 \\
\varepsilon_{33}^{T}=27 \cdot 8\end{array}$ & $18 \cdot 2$ & $\begin{array}{r}4 \cdot 58 \\
4 \cdot 7\end{array}$ \\
\hline
\end{tabular}

a Data from Jaffe and Berlincourt (1965); ' $\quad$ Physical acoustics (1964) data. 
Table 4 presents the dielectric, elastic and piezoelectric constants. The analogous data for widely used quartz single crystals of the same modification and some literature data on constants (Physical Acoustic data 1964; Jaffe and Berlincourt 1965) are also given in the table.

$\alpha-\mathrm{HgS}$ piezoelectric moduluses are almost an order of magnitude larger, than that of quartz. As for elastic properties, one can see their strong anisotropy. The crystal is soft, its Young's moduli $\left(E_{11}=s_{11}^{-1}\right)$ and $\left(E_{33}=s_{33}^{-1}\right)$ are 3.34 and 2.22 times less, than those of quartz. Note, that for $\mathrm{HgS} E_{33}$ is nearly two times larger than $E_{11}$.

\section{Conclusions}

For $\mathrm{ZnO}, \mathrm{ZnS}$ and $\mathrm{HgS}$ crystals the hydrothermal growth method is preferable to high temperature methods. The main advantages offered by hydrothermal method are low crystallization temperatures and the possibility to realize prolonged growing cycles when using the oriented seeds. It enables to obtain convenient bulky crystals with low concentration of defects, characteristic for high temperature methods. For $\mathrm{ZnS}$ and HgS hydrothermal method seems to be the only convenient route for obtaining lowtemperature modifications of these materials with homogeneous crystal structure. Appropriate techniques were developed and large single crystals of $\mathrm{ZnO}, \mathrm{ZnS}$ and $\mathrm{HgS}$, useful in piezoelectric, electro-optic and laser devices, were grown.

\section{References}

Adamov L C, Sarkisov L L and Sysoov L A 1972 Monocryst. i technica (ed.) E F Chaykovsky VNII Monocryst. Harcov 691

Alexander E, Kaiman Z N, Mardix S and Steinberger I T 1970 Philos. Mag. 211237

Ananiev T V, Dubensky K K, Ryskin A I and Hilko G I 1968 FTT 101800

Babansky M D, Stroitelev A D and Chernyshev A I 1971 Materiali Yubileynoi nauchnoi konferentsii, posviashennoi 50-letiyu gelogicheskogo obrüzovaniya v TGU, Tomsk, TGU

Brafman O, Alexander E, Fraenkel B S, Kalman Z and Steinberger I T 1964 J. Appl. Phys. 351855

Brafman $O$ and Steinberger I T 1966 Phys. Rev. 143501

Carlson S H 1967 J. Cryst. Growth 1271

Chase A B and Osmer J A $1967 \mathrm{~J}$. Am. Ceram. Soc, 50325

Chernyshev A I and Babansky M D 1977 Reaktsionnaya sposobnost veschestv, Tomsk TGU 34

Croxall D E, Ward R C C, Wallace C A and Koll R C 1974 J. Cryst. Growth 22117

Dodson E M and Savage J A 1968 J. Mater. Sci. 319

Efremova E P, Kuznetsov V A and Kotelnikov A R 1976 Krystallografia 21583

Efremova E P, Kuznetsov V A and Shikina N D 1982 Geochimia 156

Faile S P 1978 J. Cry'st. Growth 43129

Galstian V G, Morozova N K, Kuznetsov V A, Shternberg A A and Muratova V I 1980 Krystallografia 25829

Garner R W and White W B 1970 J. Cryst. Growth 7343

Greene L C, Reynolds D C, Czyzak S J and Baker W M 1958 J. Chem. Phys. 291375

Harsy M 1968 Mat. Res. Bull. 3483

Heiland G, Mollwo E and Stockman F 1959 Solid State Phys. 8121

Hirose M 1971 Jpn. J. Appl. Phys 10401

Iwanaga H, Yosiil T, Yamaguchi T and Shifeta N 1979 J. Cryst. Growth 47703

Jaffe $H$ and Berlincourt D A 1965 Piezoelectric transducer materials Proc. IEEE 571372

Kashyap Subhash C 1973 J. Appl. Phys. 444381

Kozielski M 1967 J. Cryst. Growth 1293

Kuznetsov V A, Efremova E P and Kolonin G R 1973 Geochimica 5653 
Kuznetsov V A, Efremova E P and Kotelnikov A P 1974 Geochimia 7963

Kuznetsov V A 1964 Rost Kristallov. (eds) A V Shubinkov and N N Sheftal (M: Nauka) IV 144

Kurbatov L N, Kozina G S, Kostinskaya T A, Rudnevsky V S, Lobachev A N, Kuznetsov V A, Kuzmina I P, Shaldin Yu V and Shternberg A A 1980 Kvantovaya Electr, 7378

Kuznetsov V A and Lobachov A N 1972 Kristallografia 17878

Kuzmina I P, Lobachev A N and Triodina N 1970 Issledovanie protsessov krystallizatsii v gydrotermalnych usloviyach (ed.) A N Lobachev (M: Nauka) 29

Kuznetsov V A, Nesterova Z V, Popov Yu V and Shternberg A A 1980 Optica i Spectrosk. 481028

Kuzmina I P, Nikitenko V A, Terestchenko A I, Shaldin Yu V and Lazarevskaya O A 1982 Gidrotermalny syntoz i vyrastchivanio monocrystallov. (ed.) A N Lobachev (M: Nauka) 40

Laudise R A 1963 The art and science of growing crystals (ed.) J J Gilman (New York: Wiley) 252

Laudise R A and Caporaso E D 1964 J. Am. Ceram Sac. 479

Lendway E $1971 \mathrm{~J}$. Cryst. Growth 1077

Linares R C 1968 Trans. Mat. Soc. AIME 242441

Lobachev A N, Kuzmina I P and Lazarevskaya O A 1982 Gydrotermalny syntez $i$ virastenivanic monocrystallov. (ed.) A N Lobachev (M: Nauka) 26

Lobachev A N, Kuzmina I P, Shaldin Yu V, Lazarevskaya O A and Belogurov D A 1977 Rost Krystallov iz vysokotemperaturnych vodnych rastvorov (ed.) A N Lobachev (M: Nauka) 158

Mita Y 1962 J. Phys. Soc. Jpn. 17784

Michaelski E, Demianiuk M, Kaczmerek S and Zmija J 1979 Acta Phys. Pol. A56 333

Morozova N K, Kuznetsov V A, Shternberg A A and Karetnikov I A 1979 Krystallografia 241088

Neviantseva P P, Levitskaya T D, Kidiarov B I, Demianov E A and Pasko P G 1972 Izv. Akad. Nauk SSSR Neorg. Mater. 8488

Nielsen K F 1968 J. Cryst. Growth 3-4 141

Nielsen I W and Dearborn E E $1960 \mathrm{~J}$. Phys. Chem. 641762

Nistor L C, Nistor S V and Tasczan M I 1980 J. Cryst. Growth 50557

Obuhova N F, Atroshenko L V and Kolodiashzky A I 1977 Izv. Akad. Nauk. SSSR, Neorg. Mater. 131390

Parker S G and Pinnel J E 1968 J. Cryst. Growth 3/4 490

Park J S and Reynolds D C 1967 J. Appl. Phys. 38756

Pashkovasky M V, Savitsky I V and Lutsiv R V 1961 Ukr. Fiz. Zh. 6691

Piper W W and Roth W L 1953 Phys. Rev. 92503

Pottor R W II and Barnes H L 1978 Am. Miner. 631143

Rabadanov R A, Semiletov S A and Magomedov Z A 1970 FTT 121431

Rumiantsev Yu M, Kuznetsov F A, Stroitelev S A 1965 Kristallografia 10263

Russel G J and Woods J 1979 J. Cryst. Growth 47647

Sasaki K 1975 Sci. Rep. Hirosaki Univ. 2256

Samelson H and Brophy V A 1961 J. Electrochem. Soc. 108150

Scharowsky A 1953 Z. Phys. B. 135318

Shamburov V A, Kuznetsov V A, Lobachev A N, Charitonova I V and Soshnikov V G 1970 Krystallografia 15302

Shalimova K V, Morozova N K, Malov M M, Kuznetsov V A, Shternberg A A and Lobachev A N 1974 Krystallografia 19147

Shalimova K V, Morozova N K, Kuznetsov V A, Kotelnikov A P and Veselkova M M 1974 Krystallografia 19634

Shternberg A A 1970 Issledovanie protsessov krystallizatsii v gydrotermalnych usloviyach (ed.) A N Lobachev (M: Nauka) 199

Shichiri T, Aikami T and Kakinoki J 1978 J. Cryst. Growth 43320

Shternberg A A, Kuzmina I P and Kuznetsov V A 1962 Kristallografia 7334

Sysoev L A 1972 Izv. Akad. Nauk SSSR, Neorg. Mater. 8639

Timofeeva V A 1965 Rost Kristallov (ed.) N N Sheftal (M: Nauka) VI 85

Tokarov E F, Kobiakov I B, Kuzmina I P, Lobachev A N and Pado G S 1975 FTT 17980

Toudic Y, Regreny A, Passaret M, Aumont R and Bayon J F 1972 J. Cryst. Growth 13/14 519

Wanklyn B M 1970 J. Cryst. Growth 7107

1964 Physical Acoustics (ed.) W P Mason 1 Part A

Wolf G A and LaBelle H E $1965 \mathrm{~J}$. Am. Ceram. Soc. 48441 